\title{
COMPUTER AIDED SIMULATION ANALYSIS FOR COMPUTATION OF MODAL ANALYSIS OF THE FREIGHT WAGON
}

This paper deals with theoretical and practical aspects of modal analysis, which belongs to the tests for design of new rail wagons. The paper describes the process for calculating the eigenfrequencies of the wagon with non-standard design and dimensions and strength analysis of the modified construction of bogie type Y25. This computer aided simulation analysis significantly reduces the time to verify the static and dynamic evaluation of rail vehicles.

Keywords: Modal analysis, eigenfrequencies, design, wagon frame.

\section{Introduction}

Modal analysis is a relatively young field of dynamics and in industry started to be used in the 80 s of the last century. Late inclusion into practice is associated with the development of software and hardware for finite element method. Modal analysis can be applied in theory, such as computational method or at practical level, such as real experimental measurements of mechanical structures. The modal parameters obtained from experimental analysis in engineering practice are often compared with the modal parameters obtained from computational methods [1]. The resulting modal parameter analysis include:

- eigenfrequencies of the construction,

- mode shapes,

- modal damping of the construction.

The great advantage of the mentioned simulations is that the entire development process of rolling stock is so accelerated, leading to a reduction in overall costs. Simulations and subsequent optimization of the vehicle structure is made before production of the vehicle itself. This leads to minimizing the number of unsatisfactory results conducted on a real vehicle. This may, in such a stage of development lead to delays and increased costs [2].

Computational models of vehicles and their components are more or less simplified compared with the actual ones. This simplification is seen when comparing the results from real tests.

\section{Application of modal analysis}

Modal analysis method can solve many technical problems encountered in the design, manufacture and operation of mechanical systems or parts. It is also used in the analysis of adverse events of mechanical systems, such as excessive noise, deformation, vibration, damage and so on.

Ride properties significantly influence vehicles mechanical systems [3, 4, 5] dynamic behaviour. We can theoretically predict the movement of the wheelset in the track by means of the wheelset and track geometric characteristics [6] analysis. Geometric characteristics define the rail / wheel profiles contact couple geometrical relationship. The shape of the contact couple crucial influences the size of the contact patch and contact stress between wheel and rail [7] value. This creates loading and excitation forces acting inside vehicle and track systems [8, 9]. The analysis of the mechanical systems dynamics may be analyzed by means of various methods [10].

Reasons for using modal analysis:

- Comparison of data obtained from experimental measurement on the prototype with the corresponding data obtained from finite element method. Optimization of the analytical model, which will be used for further calculations and simulations. This optimized model is free of errors, which were caused by poor application of boundary conditions.

- With the resulting eigenfrequencies unsafe operating conditions can be determined, which are not allowed. If the eigenfrequencies and frequency of excitation are equal, the resonance occurs. This reduces operating life, increases noise and could damage the construction.

- With the resulting mode shapes of vibrations we can determine the places of maximum errors. Subsequently, it is possible to make structural modifications (editing geometry, adding additional elements, changing material characteristics, etc.), which eliminate dangerous vibration.

\footnotetext{
* Pavol Stastniak, Jozef Harusinec

University of Zilina, Faculty of Mechanical Engineering, Department of Transport and Handling Machines, Zilina, Slovakia,

E-mail: pavol.stastniak@fstroj.uniza.sk
} 
- The resulting modal parameters are used to diagnose faults and places of operation.

\section{Modal analysis solved by finite element method}

The most common type of the dynamic calculation is modal analysis, which determined mode shapes, eigenfrequencies and modal damping of mechanical systems [11]. These parameters provide us with basic information on the dynamic behaviour of mechanical systems.

At present, the modal analysis of mechanical systems is performed in computer programs that operate on the principle of finite element method. The most commonly used programs include ANSYS, ADINA, COMSOL and others.

Using modal analysis by finite element proceeds as follows:

1. Create geometry of the analysed construction.

2. Define material properties (density materials, Poisson's ratio, Young's modulus of elasticity of material).

3. Define the boundary conditions for the creation of computational model.

4. Create a mesh of finite elements (Fig. 1), which consists of a suitably chosen element and its final size (smaller mesh, longer calculation)

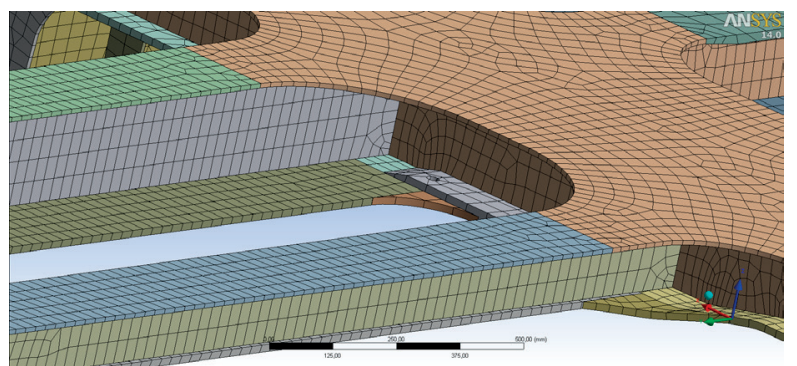

Fig. 1 The mesh of finite elements in the model of wagon

5. Set the solver which contains a suitable computational algorithm. Select the frequency range and number of wanted modes of vibrations in mechanical constructions.

6. Export modal parameters of the analysed construction.

\section{Model eigenfrequencies computations}

\subsection{Model description}

- CAD model - freight wagon for intermodal transport in Europe - WEL-WAGON [12, 13, 14],

- the dimensions of FEM model and CAD model - 1:1,

- spatial 3D elements (automatic meshing) - (15 - 30) mm [12, $13,14]$,

- standard gravity in axis $\mathrm{z}-\mathrm{g}=9.8066 \mathrm{~m} / \mathrm{s}^{2}$.

\subsection{Material model}

- engineering steel $\mathrm{S} 355 \mathrm{~J} 2 \mathrm{C}+\mathrm{N}$

- minimum yield value $355 \mathrm{MPa}$ (323 $\mathrm{MPa}$ in an immediate close distance of the weld),

- material - homogenous, isotropic, linear and elastic,

- mechanical properties - Young modulus of elasticity $\mathrm{E}=$ $210000 \mathrm{MPa}$, Poisson`s ratio $\mu=0.3$.

\subsection{Utilised software}

ANSYS software allows engineers to construct computer models of structures, machine components or systems, apply operating loads and other design criteria and study physical responses, such as stress levels, pressure, etc. [15].

\subsection{Boundary conditions}

a) boundary condition in the place of A-D (4 slides),

(The coordinate system is oriented in accordance with Fig. 2. The wagon is supported in the spots of slides. The knots in the slides spots are interconnected with spring elements having stiffness of $0.57 \mathrm{~N} / \mathrm{m}$ ),

b) boundary condition in the places $\mathrm{E}$ and $\mathrm{F}$ ( 2 hemispherical bogie pivots) - Table 1.

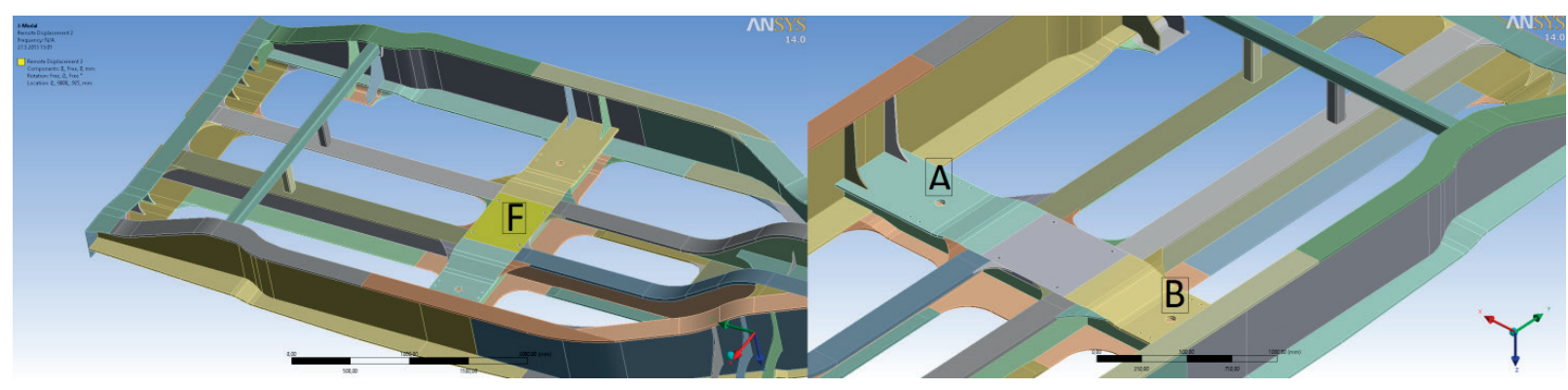

Fig. 2 The places for hemispherical bogie pivots and slides in the model of wagon (the figure shows only 1/2 of wagon, because the model is symmetric) 
Boundary condition in the hemispherical bogie pivot

Table 1

\begin{tabular}{|c|c|c|c|}
\hline $\begin{array}{c}\text { Ball point } \\
\text { No. } \mathbf{1}\end{array}$ & Condition & $\begin{array}{c}\text { Ball point } \\
\text { No. } 2\end{array}$ & Condition \\
\hline Fx & LOCK & Fx & LOCK \\
\hline Fw & LOCK & Fw & LOCK \\
\hline Fv & LOCK & Fv & FREE \\
\hline Rx & FREE & Rx & FREE \\
\hline Rw & FREE & Rw & FREE \\
\hline Rv & FREE & Rv & FREE \\
\hline
\end{tabular}

LOCK - fixed, FREE - free to the directions of movement or rotation. $F_{x}$ - displacement in the $x$ direction, $F_{y}$ - in the $\mathrm{v}$ direction, $\mathrm{F}_{\mathrm{w}}$ - in the $\mathrm{w}$ direction. $\mathrm{R}_{\mathrm{x}}$ - rotation in the $\mathrm{x}$ axis, $\mathrm{R}_{\mathrm{v}}$ - in the $\mathrm{v}$ axis, $\mathrm{R}_{\mathrm{w}}$ - in the $\mathrm{w}$ axis. The program ANSYS used to determine the direction of the symbols $\mathrm{x}, \mathrm{v}, \mathrm{w}$ instead of $\mathrm{x}, \mathrm{y}$, z) $[16,17]$

\subsection{Computation}

The bogie for wagon design is the same as the Y25 Lsd 1 wagon design and the used suspension has the kinked characteristic curve in the point of $6.63 \mathrm{t} /$ axle [ 2 and 3]. Spring rigidity: outer spring $0.5076 \mathrm{~N} / \mathrm{m}$, inner spring $0.8244 \mathrm{~N} / \mathrm{m}$ [18].

Wagon spring stiffness up to $6.63 \mathrm{t} / \mathrm{axle}$.

(acts the outer spring only)

$\mathrm{c}=8121827 \mathrm{~N} / \mathrm{m}$

Wagon springs stiffness over to $6.63 \mathrm{t}$ /axle.

(act both of springs)

$c=21312264 \mathrm{~N} / \mathrm{m}$

Unsprung mass of 1 axle:

$\mathrm{m}_{\mathrm{R}}=\mathrm{m}_{\text {wheelset }}+\mathrm{m}_{\text {axlebox }}+\mathrm{m}_{\text {springs }}$

$\mathrm{m}_{\mathrm{R}}=1072+240+(7.2+15.45) * 4=1402.6 \mathrm{~kg}$

$\mathrm{m}_{\mathrm{a}}=$ TARA $-4 * \mathrm{~m}_{\mathrm{R}}=22000-4 * 1402.6=16390 \mathrm{~kg}$
The natural angular frequency can be computed by:

$\omega=\frac{1}{2 \pi} \cdot \sqrt{\frac{c}{m_{a}}}$

Input parameters for the calculation are given in Table 2.

\subsection{Results}

It is clear from the analysis that the third loaded wagon eigenfrequency (Fig. 3) is close to the third loaded wagon suspension eigenfrequency (the difference is $0.95 \mathrm{~Hz}$ ). For further development of the wagon, its ride tests in operation performance are needed. The structural design modification for 3-rd eigenfrequency from the loaded wagon suspension is also needed. Modification can be done by using structural parts respectively assemblies and subassemblies (shape, material thickness, etc.)

\section{Strength analysis of the modified construction of bogie type Y25}

Bogie Y25 is equipped with a single suspension with duplex coil springs with kinked characteristic curve, a wheel guiding device of axle guard without clearances and with friction dampers with a special construction [19]. Transverse suspension is partially achieved through flexi-coil spring effect (clearance 2 x 10 $\mathrm{mm}$ ). The frame of the wagon is usually associated with a bogie through the hemispherical bogie pivot (radius $190 \mathrm{~mm}$ ) and its centre of $925 \mathrm{~mm}$ above the track at a weight of $20 \mathrm{t}$. The bogie

Input parameters for computation

Table 2

\begin{tabular}{|l|c|c|c|}
\hline State of load & Mass $[\mathrm{kg}]$ & Suspension stiffness $[\mathrm{N} / \mathrm{m}]$ & Eigenfrequency $[\mathrm{Hz}]$ \\
\hline Empty $-1 \mathrm{t}$ & 15390 & 8121827 & 3.66 \\
\hline Empty & 16390 & 8121827 & 3.54 \\
\hline Empty $+1 \mathrm{t}$ & 17390 & 8121827 & 3.44 \\
\hline Loaded & 80390 & 21312264 & 2.59 \\
\hline
\end{tabular}

Comparison of the calculated value of eigenfrequency and eigenfrequency of suspension is presented in Table 3.

Comparison of the results for empty and loaded wagons

Table 3

\begin{tabular}{|l|c|c|}
\hline Eigenfrequency - number & Calculated value of eigenfrequency $[\mathrm{Hz}]$ & Eigenfrequency of suspension $[\mathrm{Hz}]$ \\
\hline Empty wagon & 5.01 & 3.54 \\
\hline 1 & 5.59 & 3.54 \\
\hline 2 & 9.08 & 3.54 \\
\hline 3 & 1.52 & 2.59 \\
\hline \multicolumn{3}{|l|}{} \\
\hline 2 & 1.87 & 2.59 \\
\hline 3 & 2.1 & 2.59 \\
\hline
\end{tabular}




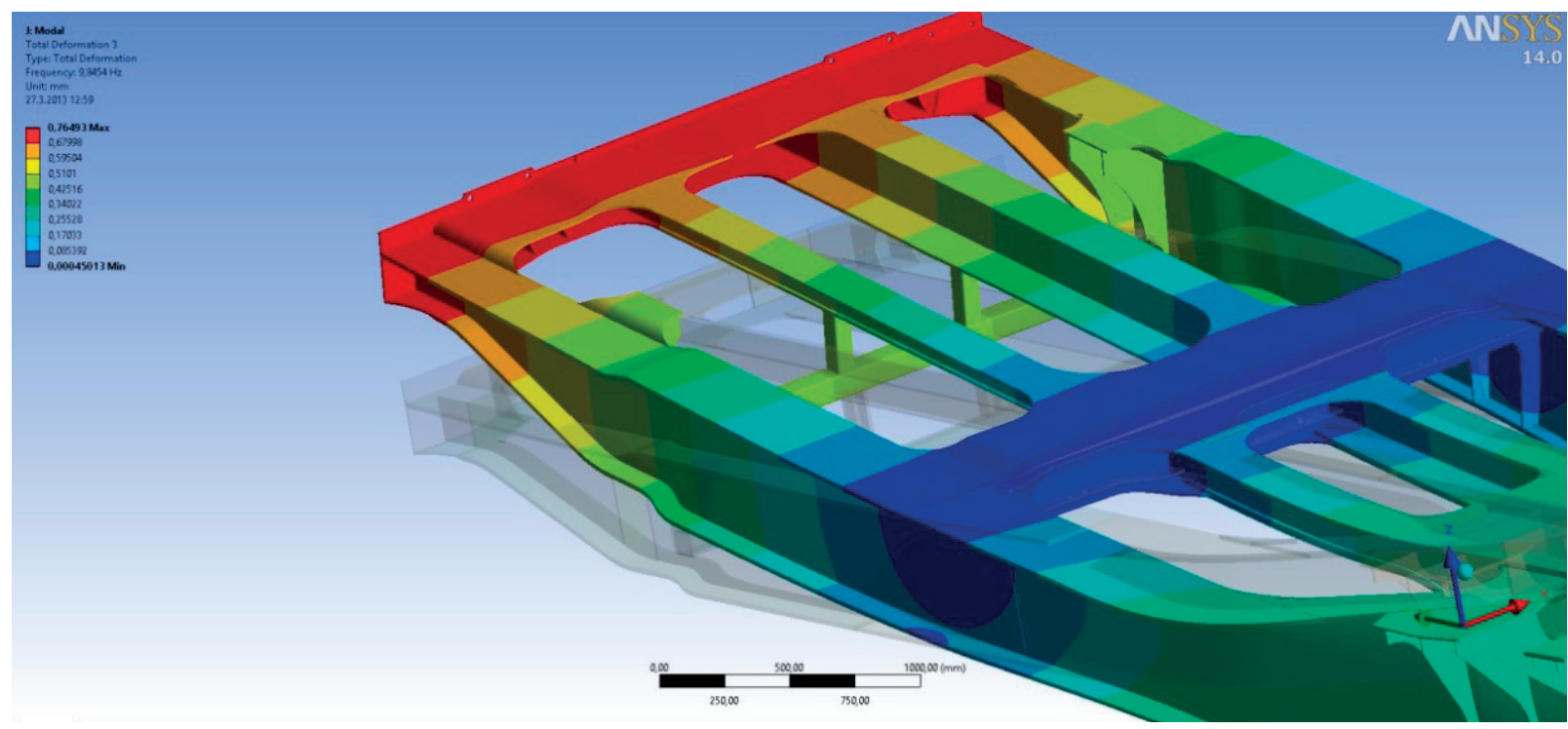

Fig. 3 Visual display of shape shifting in the third eigenfrequency in program ANSYS

was originally designed for the load of $20 \mathrm{t}$ /axle and maximum speed of $100 \mathrm{~km} / \mathrm{h}$ with a wheel base of $1800 \mathrm{~mm}$ [20]. During the development these parameters were upgraded.

At present most bogies are designed for $22.5 \mathrm{t}$ axle load and the maximum speed increased to $120 \mathrm{~km} / \mathrm{h}$. Bogies weight is usually from 4.5 to $5 \mathrm{t}$. Wheel diameter is $920 \mathrm{~mm}$ and the wheelbase is $1800 \mathrm{~mm}$. The overall width of the bogie frame is $2440 \mathrm{~mm}$, width at the centre of the axle boxes is $2000 \mathrm{~mm}$ for $1435 \mathrm{~mm}$ track gauge. 3D model of said bogie frame is shown in Fig. 4.

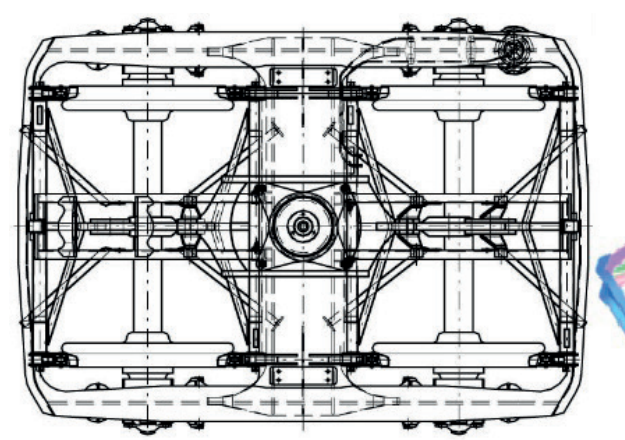

Fig. $42 D$ and 3D model of frame bogie in program ProEngineer

Dimensions of PM3 axle

Table 4

\begin{tabular}{|c|c|c|c|c|c|c|c|c|c|}
\hline \multicolumn{10}{|c|}{ Dimensions in $\mathrm{mm}$} \\
\hline \multirow{3}{*}{$\begin{array}{c}\text { Type of } \\
\text { axis }\end{array}$} & d1 & d2 & d3 & d4 & d4 & d5 & d5 & \multirow{3}{*}{ R1 } & \multirow{3}{*}{ R2 } \\
\hline & +0.052 & +0.2 & +2.0 & \multirow{2}{*}{ Nominal value } & \multirow{2}{*}{ Tolerance } & \multirow{2}{*}{ Nominal value } & \multirow{2}{*}{ Tolerance } & & \\
\hline & +0.025 & +0.12 & -0.5 & & & & & & \\
\hline \multirow{2}{*}{ PM3 } & \multirow{2}{*}{130} & \multirow{2}{*}{165} & \multirow{2}{*}{197} & \multirow{2}{*}{180} & \multirow{2}{*}{-1.0} & \multirow{2}{*}{200} & +0.045 & \multirow{2}{*}{100} & \multirow{2}{*}{25} \\
\hline & & & & & & & +0.015 & & \\
\hline
\end{tabular}

The modification brought about expansion of the bogie frame Y25 to $1520 \mathrm{~mm}$ (Russian gauge) in such a way that the geometry of the frame was changed in the cross-section $(+36 \mathrm{~mm})$. The width in the middle of the axle box after modification is $2036 \mathrm{~mm}$. Axle dimensions are given in Table 4.

The diameter of the wheel on the axle is $957 \mathrm{~mm}$. The axle load also increased from $22.5 \mathrm{t}$ to $23.5 \mathrm{t}$. Due to the rougher climate it is intended with material labelled S $355 \mathrm{~J} 2+\mathrm{N}$ (11523) which has a yield point of $355 \mathrm{MPa}$ and tensile strength 490/630 MPa. It is believed that the weight of the bogie with the adjustments is raised to about $5 \mathrm{t}$.

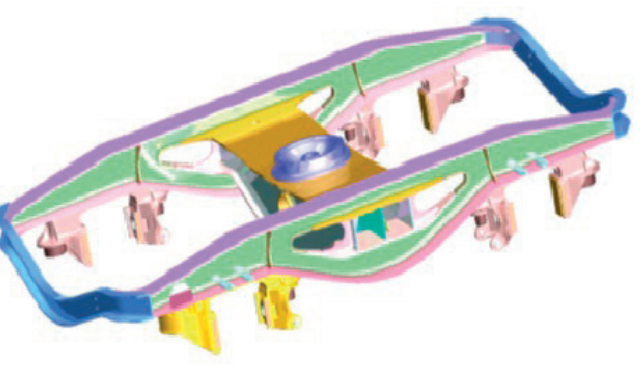




\begin{tabular}{|l|c|c|}
\hline \multicolumn{1}{|c|}{ Hemispherical bogie pivot } & Displacement & Rotation \\
\hline The direction of the longitudinal axis of the bogie (global axis $\mathrm{x})$ & $\mathrm{ux}=\mathrm{R}$ & $\mathrm{\phi x}=\mathrm{R}$ \\
\hline The direction of the transverse axis of the bogie (global axis $\mathrm{y})$ & $\mathrm{uv}=\mathrm{F}$ & $\mathrm{Q}=\mathrm{F}$ \\
\hline The direction of the vertical axis of the bogie (global axis z) & $\mathrm{uw}=\mathrm{R}$ & $\phi \mathrm{w}=\mathrm{F}$ \\
\hline
\end{tabular}

Boundary conditions - axle guard

Table 6

\begin{tabular}{|l|c|c|}
\hline \multicolumn{1}{|c|}{ Axle guard } & Displacement & Rotation \\
\hline The direction of the longitudinal axis of the bogie (global axis $\mathrm{x})$ & $\mathrm{ux}=\mathrm{F}$ & $\phi \mathrm{x}=\mathrm{F}$ \\
\hline The direction of the transverse axis of the bogie (global axis $\mathrm{y})$ & $\mathrm{uv}=\mathrm{R}$ & $\mathrm{uv}=\mathrm{F}$ \\
\hline The direction of the vertical axis of the bogie (global axis $\mathrm{z}$ ) & $\mathrm{uw}=\mathrm{F}$ & $\mathrm{\phi W}=\mathrm{F}$ \\
\hline
\end{tabular}

\subsection{Computation}

The object of the calculation is the strength test of freight bogie frame through FEM analysis. For the calculation of the analyzed parts of the bogie through finite element the program ANSYS was used. They are used as rectangular, four-node "shell" elements. The size of elements in the area under consideration is 5 to $10 \mathrm{~mm}$. The frame is stored in a cylindrical tube with the stiffness equivalent to the stiffness of the suspension. Boundary conditions are created so as to be applicable to all burdensome conditions. Analysis is performed in the linear region. Distortion analysis results due to the simplification mentioned in the introduction are practically negligible [21, 22]. Consideration is being given to the fact that the material is linearly elastic and isotropic.

\subsection{Boundary conditions}

Reactions in the longitudinal direction (x-axis) are captured in the nodes lying inside the hemispherical bogie pivot (Table 5)

Reactions in the transverse direction (y-axis) are captured in nodes of slides (Table 6).

\subsection{Elements}

\section{SHELL181 Element}

SHELL181 (Fig. 5) is suitable for the analysis of thin and medium thick shell structures. This is a four-node element with six degrees of freedom at each node: in the direction of axis $\mathrm{x}, \mathrm{y}, \mathrm{z}$ and rotation $\mathrm{x}, \mathrm{y}, \mathrm{z}$. SHELL181 is suitable for large rotation or high stress. Changes in the shell are counted in nonlinear analysis [15].

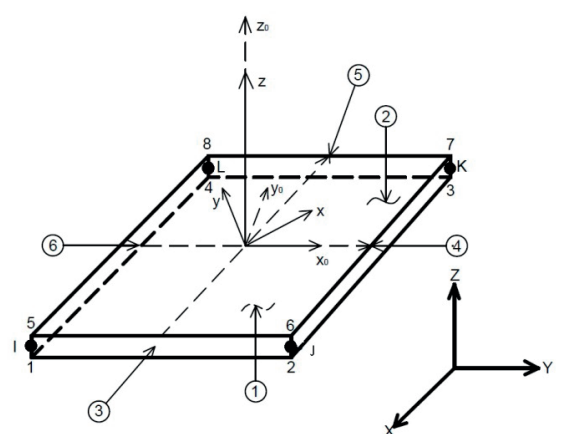

Fig. 5 Four-node element with six degrees of freedom at each node

\subsection{Load conditions}

Load conditions are as follows:

- Load condition 1 - consists of vertical force in a hemispherical bogie pivot - $824 \mathrm{kN}$.

- Load condition 2 - consists of vertical force in a hemispherical bogie pivot - $429 \mathrm{kN}$, vertical force on the slides - $107 \mathrm{kN}$ and transverse forces on the hemispherical bogie pivot - $90 \mathrm{kN}$.

Schematic view of the load condition is shown in Fig. 6 . Each component of the solid model was exported as a separate part. Contact links were created among the components (type "bonded"), which simulate the welded joints.

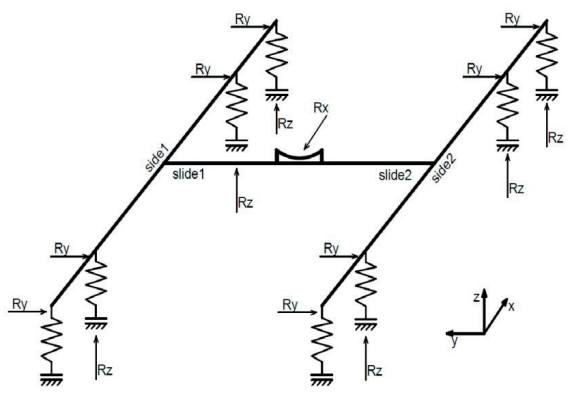

Fig. 6 Schematic view of load condition 


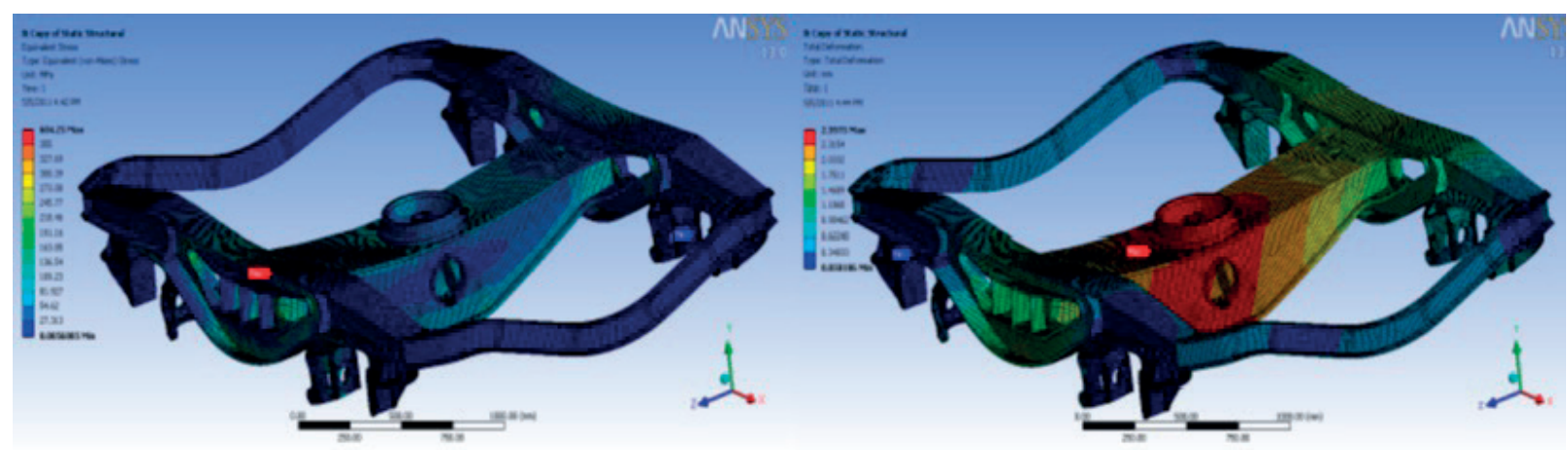

Fig. 7 The behaviour of stress and deformation in program ANSYS

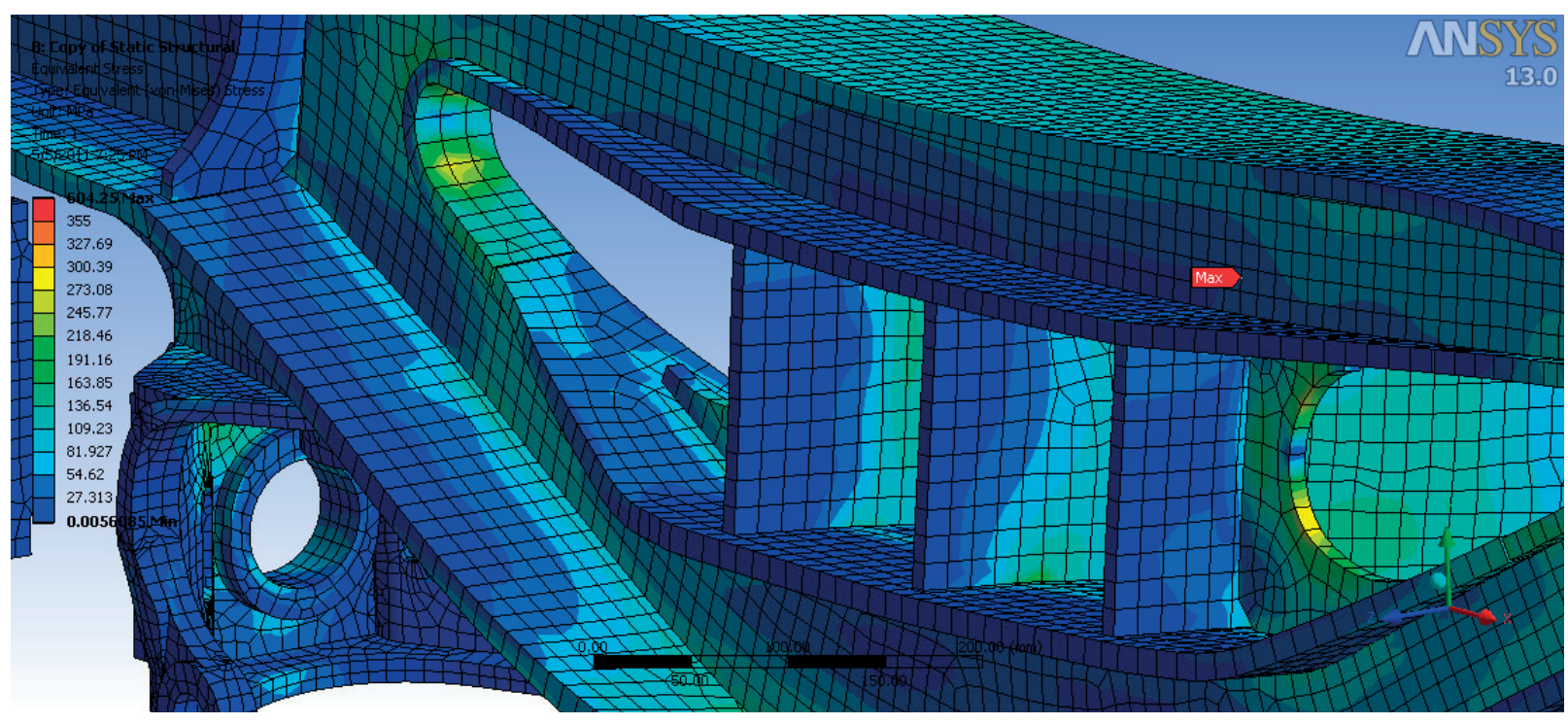

Fig. 8 Location on the model with greatest stress

\subsection{Results}

Due to the limited scope of this paper, only the results to the load condition 2 are presented. As mentioned, in this case vertical and transverse forces operated in the hemispherical bogie pivot and the slides as well. After the loading of construction in certain places the peaks incurred of stress. These deficiencies can be remedied in several ways. For example, the shape or thickness reinforcements are modified or another type of material is used.

The behaviour of stress and deformation (displacement) is shown in Fig. 7.

Figure 8 shows the location of the greatest stress.

\section{Conclusion}

Computational simulations are now an integral part of the development process of rolling stock. They allow a more detailed analysis of the behaviour of the vehicle as a whole or its individual parts. Therefore, it is possible to better optimize the design of rail vehicles and prevent potential problems in the operation, which would require increased costs.

\section{Research-Educational Centre of Rail Vehicles (VVCKV)}

\section{Acknowledgement}

This paper was created during the processing of the project No. APVV-0842-11: "Equivalent railway operation load simulator on the roller rig". The work is also supported by the Scientific Grant Agency of the Ministry of Education of the Slovak Republic and the Slovak Academy of Sciences in project No. 1/0347/12: "Railway wheel tread profile wear research under the rail vehicle in operation conditions simulation on the test bench.", project No. 1/0383/12: "The rail vehicle running properties research with the help of a computer simulation." and No. 1/1098/11: "Stress Distribution in a Braked Railway Wheel". 


\section{References}

[1] ZMINDAK, M., GRAJCIAR, I., NOZDROVICKY, J.: Modelling and Computations in Finite Element Method, Zilina, ISBN 80-968823-5, 2004.

[2] STASTNIAK, P., HARUSINEC, J., GERLICI, J., LACK, T.: Containers Transport Wagons Design (in Slovak). Dynamics of Rigid and Deformable Bodies, Usti nad Labem : University J. E. Purkyne. ISBN 978-80-7414-510-0. p. 7, 2012.

[3] NANGOLO, F., N., SOUKUP, J., SVOBODA, M.: Modelling of Vertical Dynamic Response of Railway Vehicle System with Experimental Validation. Machine Modelling and Simulation, pp. 295-302, Polytechnika Poznanska : Rokosovo, ISBN 978-83923315-2-0, 2012.

[4] SKOCILAS, J., SKOCILASOVA, B., SOUKUP, J.: Determination of the Rheological Properties of Thin Plate under Transient Vibration. Latin American J. of Solids and Structures. Brasil Society for Mechanics and Engineering. ISSN 1679-7817 (print), 1679-7825 (online).

[5] SOUKUP, J., VALES, F., VOLEK, J., SKOCILAS, J.: Transient Vibration of Thin Viscoelastic Orthotropic Plates. Acta Mechanica Sinica, vol. 27, No. 1, pp. 98 - 107. The Chinese Society of Theoretical and Applied Mechanics; Institute of Mechanics, Chinese Academy of Sciences, co-published with Springer, ISSN 0567-7718 (Print), 1614-3116 (online).

[6] GERLICI, J., LACK, T.: Railway Wheel and Rail Head Profiles Development Based on the Geometric Characteristics Shapes. Wear: An International J. on the Science and Technology of Friction, Lubrication and Wear. ISSN 0043-1648, vol. 271, No. 1-2 Sp., pp. 246-258, 2011.

[7] GERLICI, J., LACK, T.: Contact Geometry Influence on the Rail / Wheel Surface Stress Distribution. Procedia Engineering. ISSN 1877-7058, No. 1, pp. 2249-2257, 2010.

[8] LACK, T., GERLICI, J.: Tangential Stresses for Non-elliptical Contact Patch Computation by Means of Modified FASTSIM Method. IAVSD 2013, 23rd Intern. Symposium on Dynamics of Vehicles on Roads and Tracks, Qingdao, Southwest Jiaotong University Chengdu, USB key, p. 6, 2013.

[9] LACK, T., GERLICI, J.: Wheel/Rail Contact Stress Evaluation by Means of the Modified Strip Method. Communications - Scientific Letters of the University of Zilina, ISSN 1335-4205, vol. 15, No. 3, pp. 126-132, EDIS - Publishers of the University of Zilina, 2013.

[10] GERLICI, J., LACK, T.: Methods for Vehicle Vibration Analysis in Time Domain. Prace naukowe Politechniki Warszawskiej, Z. 63 , Transport, pp. 71-81, 2007, 2007.

[11] HARUSINEC, J., STASTNIAK, P., DIZO, J.: Calculations and Simulations in the Rail Vehicle Constructions Development (in Slovak). Technolog, University of Zilina: EDIS Zilina, ISBN 1337-8996, pp. 239-244, 2013.

[12] FABIAN, P., GERLICI, J., MASEK, J., MARTON, P.: Versatile, Efficient and Long Wagon for Intermodal Transport in Europe. Communications - Scientific Letters of the University of Zilina. ISSN 1335-4205, vol. 15, No. 2, pp. 118-123, 2013.

[13] VEL-WAGON: http://www.vel-wagon.eu/index.php/description. [online], 2010.

[14] FABIAN, P., GERLICI, J., MASEK, J., MARTON, P.: Development of a New Wagon for Intermodal Freight Transport. EURO-ZEL 2013. Proc. of the 21st Intern. Symposium Recent Challenges for European Railways, Zilina - Brno : Tribun EU. ISBN 978-80263-0380-0. - CD-ROM, pp. 298-306, 2013.

[15] ANSYS, user guide (part of the program package).

[16] ERRI B12/RP17, No. 8, Programme of Stresses to be carried out on Wagons with Steel Underframe and Body Structure. European Rail Research Institute, 1993.

[17] STASTNIAK, P., GERLICI, J., LACK, T., HARUSINEC, J.: Computer Aided Simulation Analysis for Computation of Modal Analysis of the Freight Wagon. Transcom 2013, Proc. of the 10th European Conference of Young Researchers and Scientists, Zilina: University of Zilina, ISBN 978-80-554-0695-4, pp. 297.

[18] EN 13749/2005 - Railway Applications - Wheelsets and Bogies - Method of Specifying the Structural Requirements of Bogie Frames.

[19] STASTNIAK, P., HARUSINEC, J., GERLICI, J., LACK, T.: Stress Analysis of the Modified Bogie Frame of Type Y25 (in Slovak). Dynamics of Rigid and Deformable Bodies, Usti nad Labem: University J. E. Purkyne. ISBN 978-80-7414-607-7. p. 8, 2013.

[20] DIZO, J., GERLICI, J., LACK, T.: The Goods Wagon Equipped by Y25 Bogies Computer Simulation Analysis. Transcom 2013, Proc. of the 10th European Conference of Young Researchers and Scientists, Zilina: University of Zilina, ISBN 978-80-554-0695-4. - pp. 63-66.

[21] EN 12663-2/2010 - Strength Requests on the Railway Vehicles Bodies Design.

[22] HARUSINEC, J., DIZO, J., STASTNIAK, P.: The Computer Simulation of the Goods Wagon Equipped by Y25 Bogies (in Slovak). Technolog, University of Zilina - EDIS Zilina, ISBN 1337-8996, pp. 245-250, 2013. 